\title{
Effects of Thermal and Electrical Properties on Porous Liver During Microwave Ablation Using Microwave Coaxial Slot Antenna
}

\author{
Suchai Pongpakpien, Wutipong Preechaphonkul, Phadungsak Rattanadecho* \\ Center of Excellence in Electromagnetic Energy Utilization in Engineering (C.E.E.E.), Department of Mechanical Engineering, \\ Faculty of Engineering, Thammasat University (Rangsit Campus), Pathumthani 12120, Thailand
}

Corresponding Author Email: ratphadu@engr.tu.ac.th

https://doi.org/10.18280/ijht.380211

Received: 22 March 2019

Accepted: 20 February 2020

\section{Keywords:}

hyperthermia, microwave ablation, porous liver, thermal conductivity, electrical conductivity

\begin{abstract}
The goal of the microwave ablation is the use of suitable microwave levels which will destroy the target tumor tissues completely without affecting the surrounding healthy tissues. To challenges these phenomena, this work proposes the investigation of porous liver heat model and blood flow including phenomena on thermal and electrical properties effect for enhancing the microwave ablation. The finite element technique is used for solving the transient heat transfer equation and transient momentum equation counterpart with the electromagnetic equation. The verification of the proposed porous model has been conducted by comparing it with the conventional bioheat model and experimental result from previous work. The effect of thermal and electrical properties on thermal transport and blood flow was analyzed. The result has shown that porous liver model agrees with the experimental result than the conventional bioheat model. The characteristic of changed thermal and electrical conductivity of target tissue in porous liver promotes heating rate and lower maximum temperature when compared with normal porous liver tissue conditions. In summary, this study gives the necessary aspects for a principle knowledge of heat transfer in the porous liver and can use as a guideline to enhance the microwave ablation efficacy in future study.
\end{abstract}

\section{INTRODUCTION}

Hyperthermia is a useful method of medicine to demolish unhealthy tissue. One important application is the treatment of the liver tumor [1]. The treatment process is achieved by increased the temperature of target tissue over $50{ }^{\circ} \mathrm{C}$ for a few minutes [2]. Above $60^{\circ} \mathrm{C}$, nearly instantaneous protein coagulation is induced, which leads to cell death $[3,4]$.

Microwave ablation (MWA) is one significant technique in liver tumor treatment. Comparing with the different energy sources, for example, laser, radiofrequency current, and ultrasound, the microwave is a good candidate for a larger ablating zone [5-10]. Because MWA is not receptive to tissue coagulated which happens in radiofrequency ablation (RFA) $[8,10]$, the temperature can reach higher and deeper than RFA [10]. The success of this treatment process depends on the fulfilled temperature throughout the ablation process, duration, input microwave power including antenna design and equipment [11].

To enhance MWA, several antenna designs has been developed such as cooled-shaft antenna $[12,13]$, tri-axial [14, 15], floating sleeve antenna [16, 17], and slot antenna [18, 19]. Because of suitable size and high effectiveness, the slot antenna is the most popular in the treatment process [4, 20, 21]. The slot antenna gives a heating pattern uniform and spherical, which is suitable for cancer cell shape [22]. However, the lesion looks like a teardrop shape, which the detrimental heating is unnecessary heating because it damages normal tissue near the antenna insertion path [8]. Keangin et al. [11] present the study on the effect of antenna types. The result shows good performance of MWA however, slot microwave antenna still gives the detrimental backward heating and effect to surrounding normal tissues. This is a limitation of the slot antenna even with recent improvement strategies. Because of this backward heating challenge, several the MWA antenna designs have been presented [23-25]. The backward heating remains a serious effect in MWA process. The key study in antenna design is the simulation of the precious heat transfer model. It is one of benefit tool to enhance MWA treatment process. Unfortunately, there are few studies in the realistic physical model of liver cancer. Maybe because of the complexity of the biological tissue comprise many vessels. Moreover, in realistic, the biological tissue, such as liver tissue including cell and microvascular bed with the blood flow direction contains many vessels and can be considered as a porous structure. So that the study of heat transport in biological tissue should use porous media theory [26-28]. The porous media theory is the most suitable theory for heat transfer in biological tissue. Because of a few assumptions when compared to different bioheat model [27]. Only a few studies that considered the heat transfer model with the porous media theory, especially the effect of blood flow and their properties effect. The properly mathematical model is valuable for the improvement of hyperthermia technologies, and the enhancing of the MWA process for human liver cancer treatment technology.

In this study, the porous liver model with the energy equation and momentum equation has proposed. The influences of thermal and electrical conductivity factors have been investigated. The blood velocity profile, temperature 
distribution, in the ablation zone have been investigated. The two layers of porous liver tissue, tumor layer, and normal tissue layer, model is proposed. The transient momentum equation (Brinkman model extended with Darcy model) together with the transient energy equation including with electromagnetic equation, are conducted. The simulation equation and boundary conditions calculated by using the axisymmetric finite element method via COMSOL $^{\mathrm{TM}}$ Multiphysics. The proposed model has verified with a previous work bioheat model and experimental result with the same conditions. The simulation results of temperature distribution, blood velocity profile with influences of thermal and electrical conductivity factors are presented in detail. The investigation gives the essential aspect of a fundamental understanding of heat transport within porous liver cancer and can be used as a guideline to enhance the efficacy design of the MWA process.

\section{SIMULATION METHODOLOGY}

\subsection{Slot microwave antenna model}

The single slot microwave antenna has used because of the appropriate size for insertion into the human liver. The antenna is composed of a thin semi-rigid coaxial cable. Since the antenna is intended to be inserted into the human liver, the outer diameter is as small as possible. This antenna has a diameter of $1.79 \mathrm{~mm}$. because the thin antenna is required in the interstitial treatments. A ring-shaped slot, $1 \mathrm{~mm}$. wide is cut off the outer conductor $5.5 \mathrm{~mm}$. in length from the shortcircuited tip of the antenna to allow electromagnetic wave propagation into the liver because the effective heating around the tip of the antenna is very important to the interstitial heating and because the electric field becomes stronger near the slot [11]. The antennas are composed of an inner conductor, a dielectric and an outer conductor. Figure 1 shows the model geometry of a slot microwave antenna. The antenna is operated at the frequency of $2.45 \mathrm{GHz}$, a widely used frequency in MWA and is one of the Industrial Scientific and Medical (ISM) dedicated frequencies. Dimensions of a slot microwave antenna are given in Table 1 . While the dielectric properties of a slot microwave antenna are given in Table 2 . $[11,19]$.

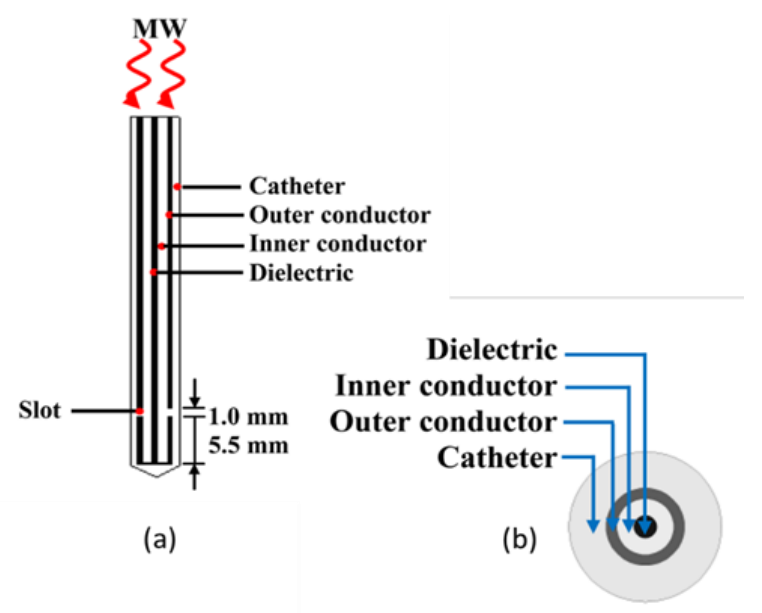

Figure 1. Structure of the antenna (a) schematic of single slot antenna (b) cross section of single slot antenna [11, 19]
Table 1. Dimensions of a slot microwave antenna

\begin{tabular}{cc}
\hline Materials & Dimensions $(\mathbf{m m})$ \\
\hline Inner conductor & 0.135 (radial) \\
Dielectric & 0.335 (radial) \\
Outer conductor & 0.460 (radial) \\
Catheter & 0.895 (radial) \\
Slot & 1.000 (wide) \\
\hline
\end{tabular}

Table 2. The dielectric properties of a slot microwave antenna

\begin{tabular}{cccc}
\hline Properties & Dielectric & Catheter & Slot \\
\hline Relative permittivity, $\varepsilon_{r}(-)$ & 2.03 & 2.1 & 1 \\
Electric conductivity, $\sigma(\mathrm{S} / \mathrm{m})$ & 0 & 0 & 0 \\
Relative permeability, $\mu_{r}(-)$ & 1 & 1 & 1 \\
\hline
\end{tabular}

\subsection{Porous liver model}

The porous liver can be separated into three main parts. Which are blood vessels, cells, and interstitial space [26, 27]. The porous liver can simplicity considered into two distinct regions. One is the vascular region (blood vessels/fluids phase). Another one is the extravascular region (tissue cell and interstitial space/solid phase). Which assumes that the whole anatomical structure as a fluid-saturated porous medium through the blood infiltrates [27]. Most previous studied [26, $27,29]$ have categorized into two distinct regions, the vascular region (blood vessels) and the extravascular region (cells and the interstitial space) and the whole anatomical structure can be treated as a blood-saturated tissue represented by a porous matrix in which the blood infiltrates through. The vascular region refers to a blood phase and the solid matrix phase is regarded as an extravascular region, as explained in Figure 2. In Figure 2 has shown the computational domain of the porous liver model structure of two parts, the tumor, and normal tissue [11]. The anatomical structure of porous liver tissue is assumed to have space between cells that are filled with blood (blood-saturated porous media). In cylindrical porous liver tissue have a spherical tumor with a diameter of $20 \mathrm{~mm}$. The axis-symmetric model is used to minimizing the calculation time which maintains a good resolution. The thermal conductivity properties and dielectric properties of normal tissues and the tumor has given in Table 3 [28-30], where the microwave frequency of $2.45 \mathrm{GHz}$ is considered.

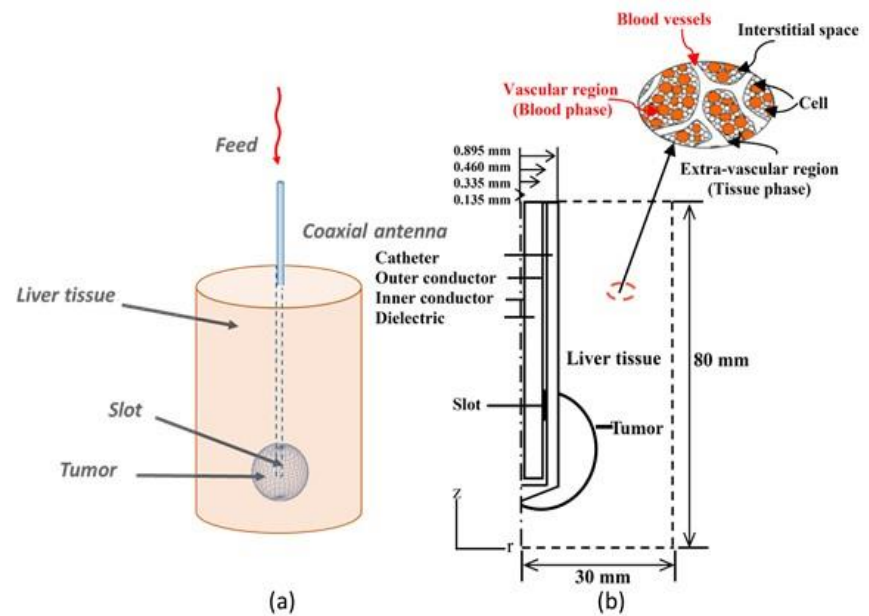

Figure 2. Axis symmetrical model structure and two layers porous liver (a) 3D porous media model (b) 2D axis symmetric model 
Table 3. Properties of tissue, blood and tumor [28-30]

\begin{tabular}{cccc}
\hline Properties & Normal tissue $(\mathbf{n})$ & Blood (b) & Tumor (t) \\
\hline Thermal Conduct $\mathrm{K}\left(\mathrm{W} / \mathrm{m}^{\circ} \mathrm{C}\right)$ & 0.497 & 0.45 & 0.57 \\
Density $\rho\left(\mathrm{kg} / \mathrm{m}^{3}\right)$ & 1,030 & 1,058 & 1,040 \\
Specific heat capacity $C_{p}\left(\mathrm{~J} / \mathrm{kg} .{ }^{\circ} \mathrm{C}\right)$ & 3,600 & 3,960 & 3,960 \\
Relative Permittivity $\varepsilon_{\mathrm{r}}$ & 43.00 & 58.30 & 48.16 \\
Electric conductivity $\sigma(\mathrm{S} / \mathrm{m})$ & 1.69 & 2.54 & 2.096 \\
\hline
\end{tabular}

\section{THE MATHEMATICAL MODEL}

The electromagnetic field propagation in microwave coaxial antenna and equation for heat transfer with blood flow is described as following:

\subsection{Electromagnetic field propagation}

The axisymmetric finite element model used in this study adapted from a single slot microwave coaxial antenna general model $[19,30]$. The equation of electric field and magnetic fields in the Transverse Electromagnetic field (TEM), which propagate in the coaxial antenna, is described in symmetrical cylindrical coordinates (2D axis r-z).

Electric field

$$
\vec{E}=e_{r} \frac{C}{r} e^{j(\omega t-k z)}
$$

Magnetic field

$$
\vec{H}=e_{\varphi} \frac{C}{r Z} e^{j(\omega t-k Z)}
$$

where,

$$
C=\sqrt{\frac{Z P}{\pi \cdot \ln \left(r_{\text {outer }} / r_{\text {inner }}\right)}}
$$

In Figure 2 has shown the inner dielectric radius $\left(r_{\text {outer }}\right)$ and the outer dielectric radius $\left(r_{\text {inner }}\right)$ respectively.

In a typical MWA using a slot antenna, the thermal energy created from the conversion of the magnetic energy when the magnetic field radiated to the target porous liver. The Transverse Magnetic field is represented by the equation as follow:

$$
\nabla \times\left[\left[\varepsilon_{r}-\frac{j \sigma}{\omega \varepsilon_{0}}\right]^{-1} \nabla \times \vec{H}_{\varphi}\right]-\mu_{r} k_{0}^{2} \vec{H}_{\varphi}=0
$$

where, $\varepsilon_{0}=8.8542 \times 10^{-12} \mathrm{~F} / \mathrm{m} \mathrm{[11]}$

Meanwhile, the boundary conditions for axis symmetry at $r$ $=0$, boundary condition for porous liver, slot antenna, boundary condition and electromagnetic wave propagation assumption have been obtained from previous literature [31]. Therefore Figure 3 has shown the detail of the boundary condition for this study.

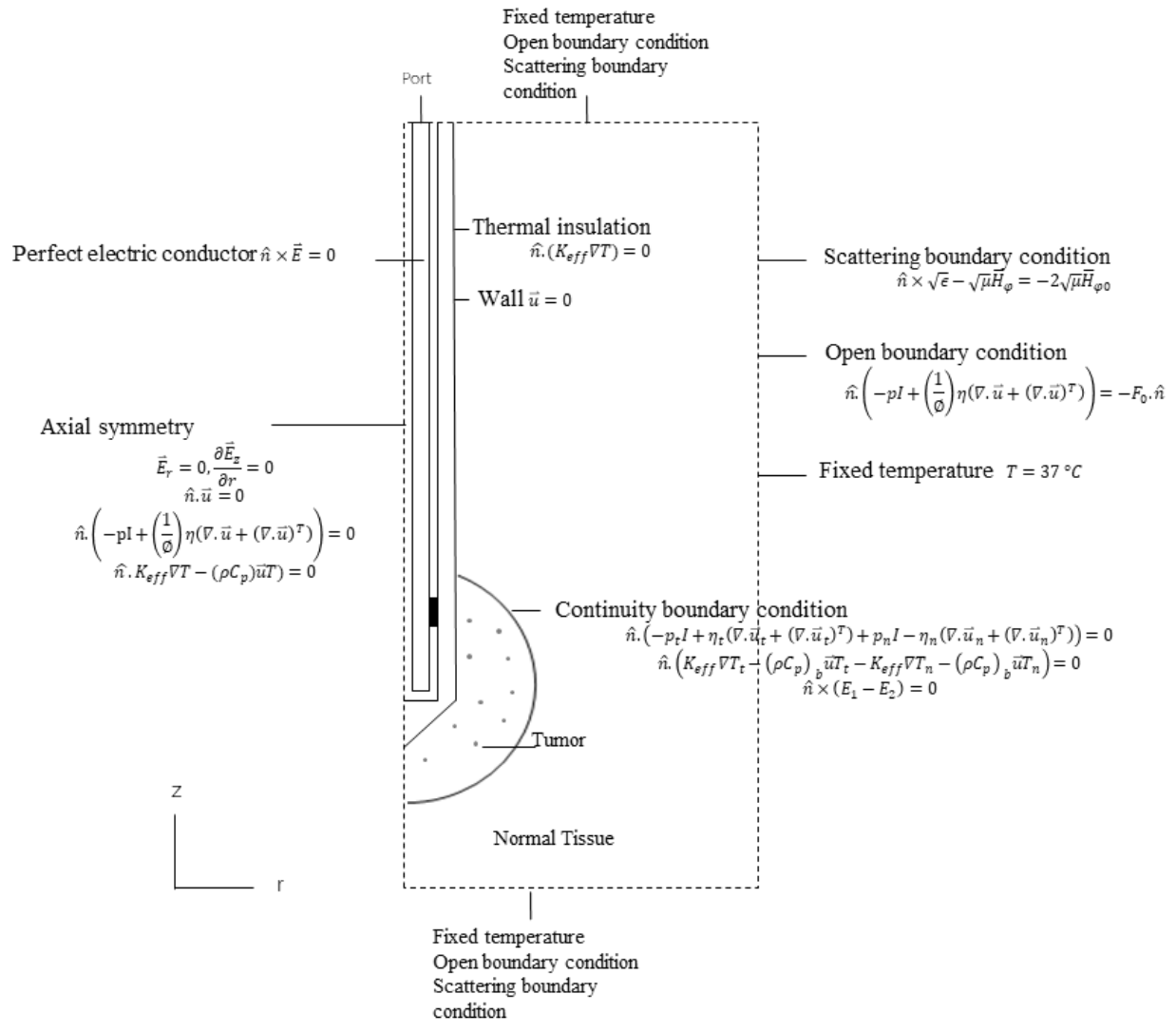

Figure 3. Boundary conditions for analysis [31] 


\subsection{Equation for blood flow and thermal transport}

To study the transient temperature distribution within the porous liver tumor and normal tissue as shown in Figure 3, the coupled model of electromagnetic wave propagation, blood flow, and thermal transport have analyzed. Due to reducing the complexity of problem-solving, the surrounding of the porous liver is equal to $37^{\circ} \mathrm{C}$ (normal body temperature) as fixed temperature except at the outer surface between the antenna and the porous liver, the adiabatic boundary condition has been considered. For simplicity, several assumptions have been obtained from our previous worked [31].

\subsubsection{Momentum equation}

To describe the blood flow phenomenon in porous liver tumor and normal tissue, Brinkman model extended Darcy model is used [32]. The equations that explained the blood flow in the porous liver are given from the continuity Eq. (5) and momentum Eqns. (6) and (7) as follows [31]:

$$
\begin{gathered}
\frac{\partial u}{\partial r}+\frac{\partial w}{\partial z}=0 \\
\frac{1}{\emptyset}\left[\frac{\partial u}{\partial t}\right]+\frac{1}{\emptyset^{2}}\left[u \frac{\partial u}{\partial r}+w \frac{\partial u}{\partial z}\right]=-\frac{1}{\rho_{b}}\left[\frac{\partial p}{\partial r}\right]+\frac{v}{\emptyset}\left[\frac{\partial^{2} u}{\partial r^{2}}+\right. \\
\left.\frac{\partial^{2} u}{\partial z^{2}}\right]-\frac{u v}{\kappa} \\
\frac{1}{\varnothing}\left[\frac{\partial w}{\partial t}\right]+\frac{1}{\emptyset^{2}}\left[u \frac{\partial w}{\partial r}+w \frac{\partial w}{\partial z}\right]=-\frac{1}{\rho_{b}}\left[\frac{\partial p}{\partial z}\right]+\frac{v}{\emptyset}\left[\frac{\partial^{2} w}{\partial r^{2}}+\right. \\
\left.\frac{\partial^{2} w}{\partial z^{2}}\right]-\frac{w v}{\kappa}+g \beta\left(T-T_{\infty}\right)
\end{gathered}
$$

The tumor porosity $\left(\phi_{\text {tumor }}\right)=0.7$ and normal tissue porosity $\left(\phi_{n_{-} \text {tissue }}\right)=0.6$. The kinematics viscosity $(v)=3.78 \times 10^{-7} \mathrm{~m}^{2} / \mathrm{s}$, the coefficient of thermal expansion $(\beta)=11 \times 10^{-4} \mathrm{~K}^{-1}$. The permeability $(\kappa)$ can be calculated by the following equation [31]:

$$
\kappa=\frac{\emptyset^{3} d_{p}^{2}}{175(1-\emptyset)^{2}}
$$

where, diameter of cell tissue $\left(d_{p}\right)=1 \times 10^{-4} \mathrm{~m}^{2}$

\subsubsection{Energy equation}

The transient energy equation assumes that the temperature of solid and blood phases, are identical. The microwave energy is included [31]. The thermal phenomena that created in porous liver tumor has been described as:

$$
\begin{aligned}
\left(\rho C_{p}\right)_{e f f} \frac{\partial T}{\partial t}+\left(\rho C_{p}\right)_{b}\left[u \frac{\partial T}{\partial r}+w \frac{\partial T}{\partial z}\right] & \\
& =K_{e f f}\left[\frac{\partial^{2} T}{\partial r^{2}}+\frac{\partial^{2} T}{\partial z^{2}}\right]+Q_{m e t} \\
& +Q_{\text {ext }}
\end{aligned}
$$

where

$$
\begin{gathered}
\left(\rho C_{p}\right)_{e f f}=(1-\emptyset)\left(\rho C_{p}\right)_{t}+\emptyset\left(\rho C_{p}\right)_{b} \\
K_{e f f}=(1-\emptyset) K_{t}+\emptyset K_{b}
\end{gathered}
$$

The external heat source $\left(Q_{\text {ext }}\right)$ have been created by the electromagnetic and assumes created from tissue/solid phase only that can be expressed as [31]:

$$
Q_{e x t}=\frac{\sigma|\vec{E}|^{2}}{2}
$$

The metabolic heat source $\left(Q_{m e t}\right)$ in this study is set to be $33,800 \mathrm{~W} / \mathrm{m}^{3}$ [11]. The blood flow boundary condition and thermal transport have been described in Figure 3 [31]. Initially, the porous liver temperature is assumed to be fixed at $37^{\circ} \mathrm{C}$, blood velocity and pressure are equal to $0 \mathrm{~m} / \mathrm{s}$ and $0 \mathrm{~Pa}$, respectively.

\section{CALCULATION PROCEDURE}

The transient phenomenon has analyzed by using the finite element method based on $\mathrm{COMSOL}^{\mathrm{TM}}$ multiphysics. The two models of an electromagnetic equation with blood flow equation and heat transport are conducted. The temperature distribution, blood flow and ablation area that occur in the porous liver are described. The simulation starts from calculating electromagnetic wave which creates heat sources in terms of an external heat source. Then calculate the timedependent temperature that occurs in the porous liver. The calculation process has continued until the target heating time. The axisymmetric finite element method model used the triangular element with Lagrange quadratic shape functions. The partial differential equation with the designed boundary is conducted. The simulation has conducted until the stability result in which the independent fine mesh is to be around 22,405 .

\section{RESULT AND DISCUSSION}

\subsection{The model verification}

The verification of the present porous liver model is compared with the simulation result of Keangin et al. [11] and

\begin{tabular}{|c|c|c|}
\hline \multirow{2}{*}{ Position (mm) } & \multicolumn{2}{|c|}{$\begin{array}{c}\text { Comparisons of Standard deviation of } \\
\text { residuals with Yang result [30] }\end{array}$} \\
\hline & $\begin{array}{c}\text { Bioheat } \\
\text { (Keangin et al.) [11] }\end{array}$ & $\begin{array}{l}\text { Porous liver } \\
\text { (Present study) }\end{array}$ \\
\hline $4.5 \mathrm{~mm}$ & 10.01 & 4.84 \\
\hline $9.5 \mathrm{~mm}$. & 4.59 & 2.94 \\
\hline
\end{tabular}
experimental result of Yang et al. [30]. All condition has been set in the same condition input microwave power $75 \mathrm{~W}$ with frequency $2.45 \mathrm{GHz}$ with the temperature starts from $8^{\circ} \mathrm{C}$. The validation results have been shown in Figure 4 for the temperature distribution in the porous liver tissue at position $4.5 \mathrm{~mm}$. and $9.5 \mathrm{~mm}$. away from the slot antenna. The antenna insert depth is $20 \mathrm{~mm}$. The result has been shown that the porous model is better to comply with experimental data than the conventional bioheat at the same approximate time range.

Table 4. Comparisons of Standard deviation of residuals with Yang result [30]

Because of the porous liver model show performance with convective heat together with conduction heat, while the conventional bioheat is contained with only conduction heat mode. The standard deviation of residuals different temperature data between the porous liver model and bioheat model [11] with experimental data [30] have been shown in Table 4. The conventional bioheat model compares with the 
porous liver model has a higher deviation at both positions $4.5 \mathrm{~mm}$ and $9.5 \mathrm{~mm}$. From the comparison result in Figure 4 and Table 4, the proposed porous liver model base on a porous media approach is reasonable and can be used effectively for this problem. This is important to obtain the approaching realistic tissue modeling in the MWA process.

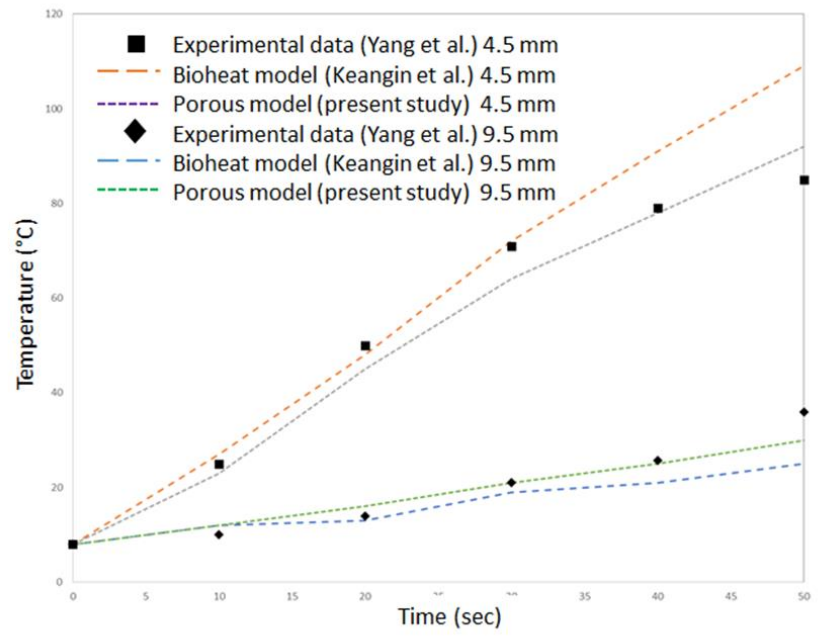

Figure 4. The verification result of the porous liver model

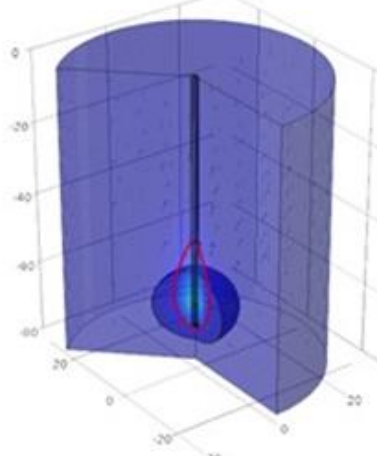

(a) $50 \mathrm{sec}$

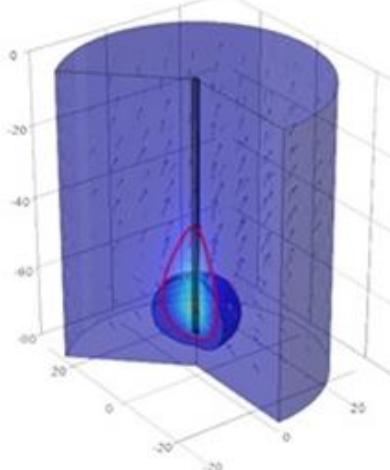

(b) $100 \mathrm{sec}$

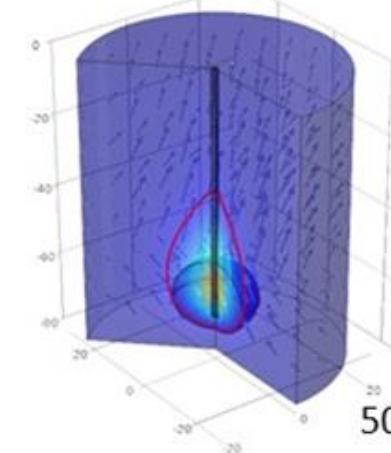

(c) $200 \mathrm{sec}$
In this study, the porous liver model has been studied for prediction when the key properties in the model have changed. The influence of two keys properties, the thermal conductivity $(\mathrm{K})$ and electrical conductivity $(\sigma)$ on the temperature distribution in the porous liver with blood flow have been investigated. The tumor is the spherical shape with a diameter of $10 \mathrm{~mm}$. A study of each parameter has conducted to investigate the result of each factor separately.

\subsection{The influence of thermal conductivity in proposed porous liver model}

Figure 5(a)-5(d) has shown simulation results of the porous liver model with the heat contour, vector pattern of blood flow in different heating time, 50, 100, 200 and 300 sec. respectively. The velocity profile has shown the same direction as the temperature profiles. The buoyancy effect has been driven by blood flow base on the microwave energy. The warmer with lower density rise near the slot antenna which higher density and colder come to replace. It can be obtained that the blood velocity depends on how to increase the temperature in the porous liver. The result of Figure 5 has been shown that the blood velocity has the same characteristic with temperature in the porous liver.

Figure 5. The blood flow vector in the different heating time: (a) $50 \mathrm{sec}$. (b) $100 \mathrm{sec}$. (c) $200 \mathrm{sec}$. and (d) $300 \mathrm{sec}$

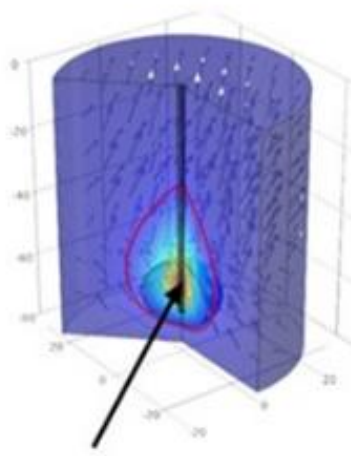

$\mathrm{T}_{\max }: 118.9^{\circ} \mathrm{C}$

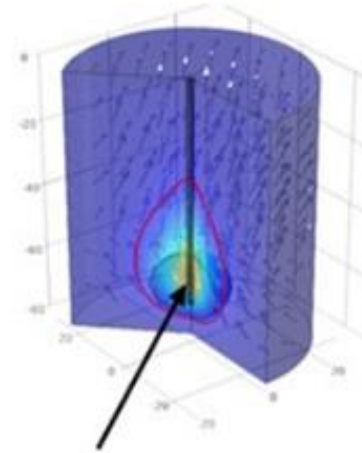

$\mathrm{T}_{\max }: 111.5^{\circ} \mathrm{C}$

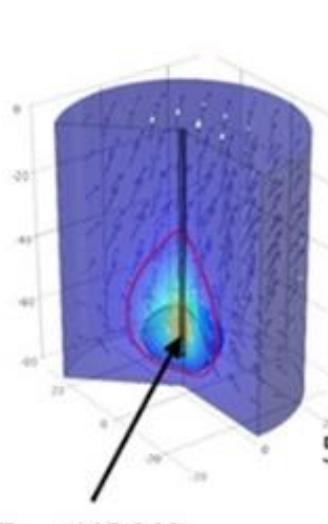

$\mathrm{T}_{\max }: 105.8^{\circ} \mathrm{C}$

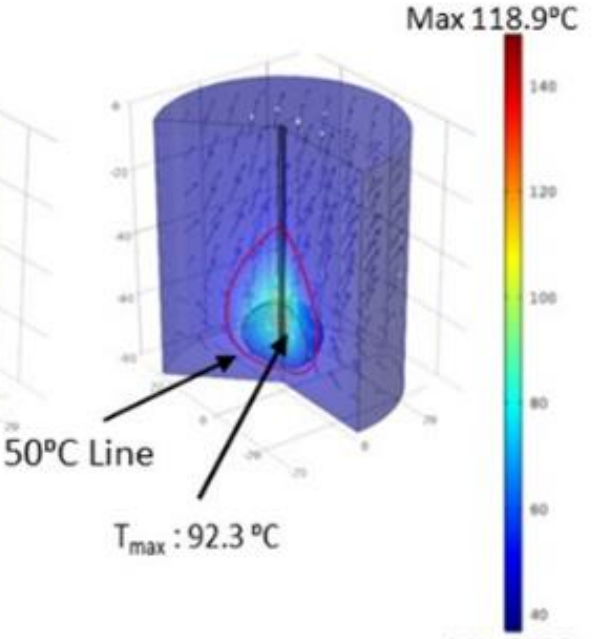

Min $37^{\circ} \mathrm{C}$

Figure 6. The temperature pattern within the porous liver at various thermal conductivity: (a) Normal tumor tissue condition (b) Increase 1.5 time (c) Increase 2 time (d) Increase 4 time of normal tumor condition 


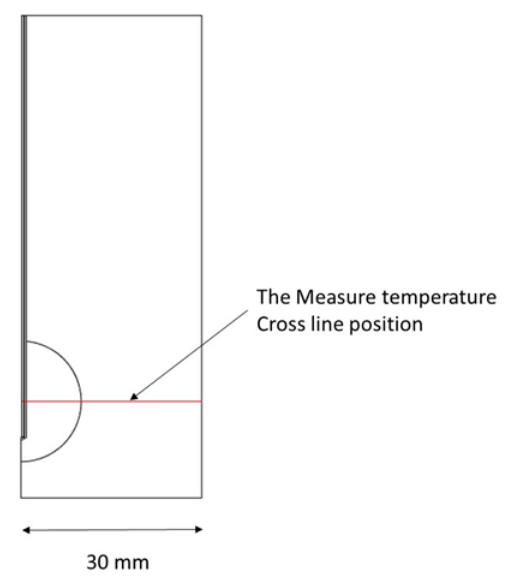

Figure 7. The temperature measure cross line position

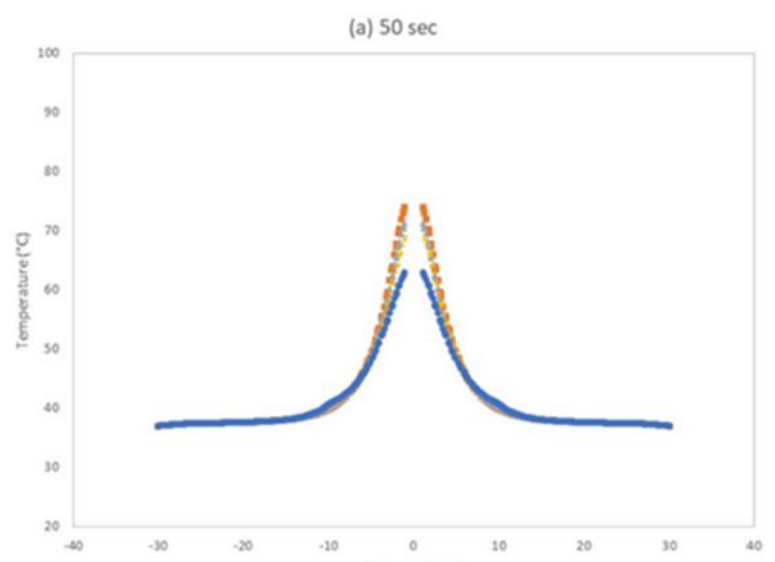

(b) $100 \mathrm{sec}$

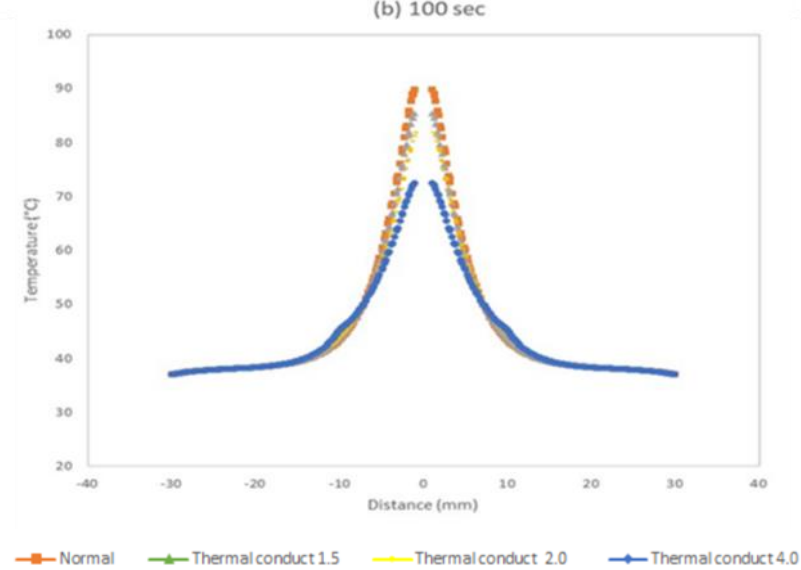

Figure 8. Tissue temperature the cross-section of the axial and transverse planes at various porous liver thermal conductivity properties for the different heating time: (a) temperature distribution at $50 \mathrm{sec}$. (b) temperature distribution at $100 \mathrm{sec}$

In this study, the influences of thermal conductivity in the porous liver with blood flow are investigated. The effective performance of MWA depends on the characteristic of the temperature profile, which determines by the key property thermal and electrical conductivity. The simulation of various thermal conductivity properties in the porous liver has been conducted. The heating time is $300 \mathrm{sec}$. and microwave input power $(P)$ equal 10 watts. Figure 6 (a) - 6 (d) has shown the temperature profile and blood flow profile within the porous liver. The various thermal conductivities of tumors have been investigated by increasing $1.5,2.0$, and 4.0 times of normal tumor condition respectively. Figure 6 has shown the hot spot zone, maximum temperature and blood velocity for each condition. As previously mentioned, the MWA process achievement when the temperature of the tumor increases to more than $50^{\circ} \mathrm{C}$ in which the tumor is destroyed so that the contour line $50^{\circ} \mathrm{C}$ has been indicated with the red line to show the area of $50^{\circ} \mathrm{C}$. The higher velocity profile has found when the maximum temperature rises. It is found that the maximum temperature decreases when the thermal conductivity increase. For more investigation, the temperature and blood velocity profile for various thermal conductivity along with the cross section are investigated. Figure 7 has shown the cross-line section of the measuring point. The measured temperature along the cross-section with different thermal conductivity are illustrated in Figure 8 (a)-8 (b). It is found that the increased thermal conductivity leads to a decrease in the maximum temperature in the porous liver. Since the convection heat and the buoyancy force play role in the porous liver model, the heat transfer and blood flow have been distributing rapidly and absorb the maximum temperature quite well. It can be observed that thermal conductivity has affected the temperature and blood velocity in the opposite direction, increase the thermal conductivity made the maximum temperature down.

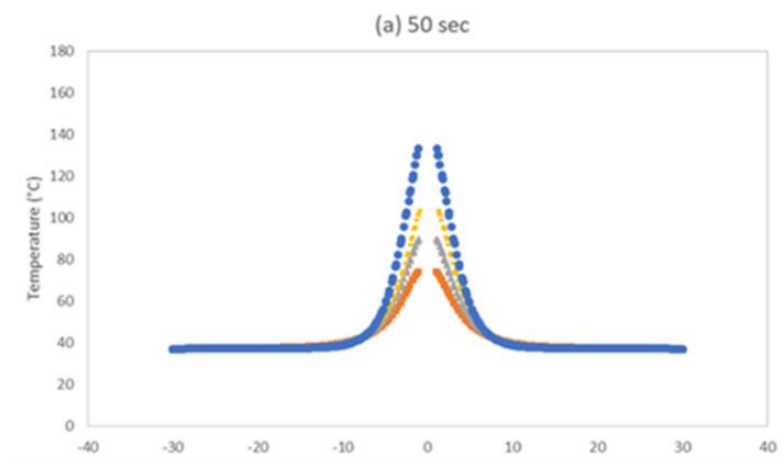

(b) $100 \mathrm{sec}$

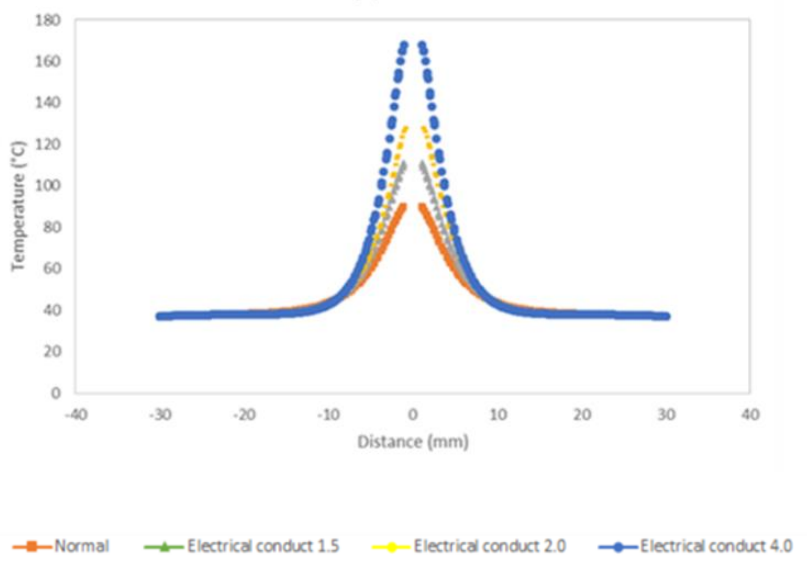

Figure 9. Tissue temperature along the cross section of the axial and transverse planes at various porous liver electrical conductivity properties for the different heating time: (a) temperature distribution at $50 \mathrm{sec}$. (b) temperature distribution at $100 \mathrm{sec}$

\subsection{The influence of electrical conductivity in the proposed porous liver model}

The effect of electrical conductivity in the porous liver with 
convection influence is investigated. The electrical conductivity has been increased 1.5, 2.0 and 4.0 times are selected for study and demonstration. The heating time is 300 sec. and microwave input power $(P)$ equal 10 watts. Figure 9 (a)-9 (b) shows the temperature distribution. It is found that the highest temperature occurs near the antenna and decreases along with the distance. The temperature of the tumor is higher than the temperature occurs in the normal tissue corresponds to the effects of the dielectric of the tumor higher than normal tissue. The increase in electrical conductivity brings about an increase in maximum temperature and an increasing temperature rising rate. The blood flow velocity also shows the same phenomenon as the temperature profile. This is because of an increase in electrical conductivity $(\sigma)$ results in a higher heat generation rate of $Q_{e x t}$ term in Eq. 12 and cause the temperature increase in the porous liver. It can investigate that the increased electrical conductivity brings about the increase of maximum temperature as well as blood flow characteristic because of $Q_{\text {ext }}$ term in Eq. 12 effects as the previous mention.

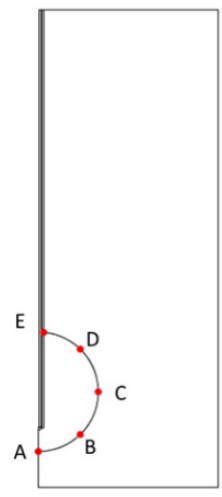

Figure 10. The temperature measuring position along with the arc of tumor

\subsection{The influence of thermal and electrical conductivity for ablation lesion in the target zone}

The effectiveness of the MWA process is to elevate the precision of the ablation area without effect the healthy tissue around the tumor. In this section, the effects of thermal property in the ablation zone in the porous liver with blood flow model have been investigated. Figure 10 has shown the geometry of the temperature measurement point along with the arc of the tumor. The microwave input power is 10 watts. Figure 11 (a)-11(d) have shown the result of temperature at each measurement point within the various thermal properties. It is found that the higher thermal conductivity, cause the lower maximum temperature as the previous mention. Furthermore, higher thermal conductivity such as 100 or 1000 times resulting in a smaller variation of temperature in the porous liver. This is because of high thermal conductivity will generate heat to all area rapidly with blood flow and make temperature distribute in a uniform shape. Figure 12 has shown the temperature contour when the thermal and electrical conductivity increases to 3 times compare to normal tissue. The microwave power stop when a $50^{\circ} \mathrm{C}$ contour line (red line) reaches the edge of the tumor point $\mathrm{C}$ in Figure 10. Figure 12 (a) has shown simulation results of the $50^{\circ} \mathrm{C}$ contour for normal tissue property and (b) has shown the simulation result for the thermal and electrical conductivity increase to 3 times. Even though simulation time over 300 seconds, in case of normal tissue Figure 12 (a) the $50^{\circ} \mathrm{C}$ contours still not reach the tumor edge (simulation time stop at $1000 \mathrm{sec}$.). Figure 12(b) has shown uniform lesion and less effect the around healthy tissue with shorter backward heating with simulation time 200 seconds. In the case of normal tissue property, Figure 12 (a), backward heating tail long $12 \mathrm{~mm}$. and Figure 12 (b), backward heating tail long $4 \mathrm{~mm}$. It has shown the improve performance of MWA from these comparisons.
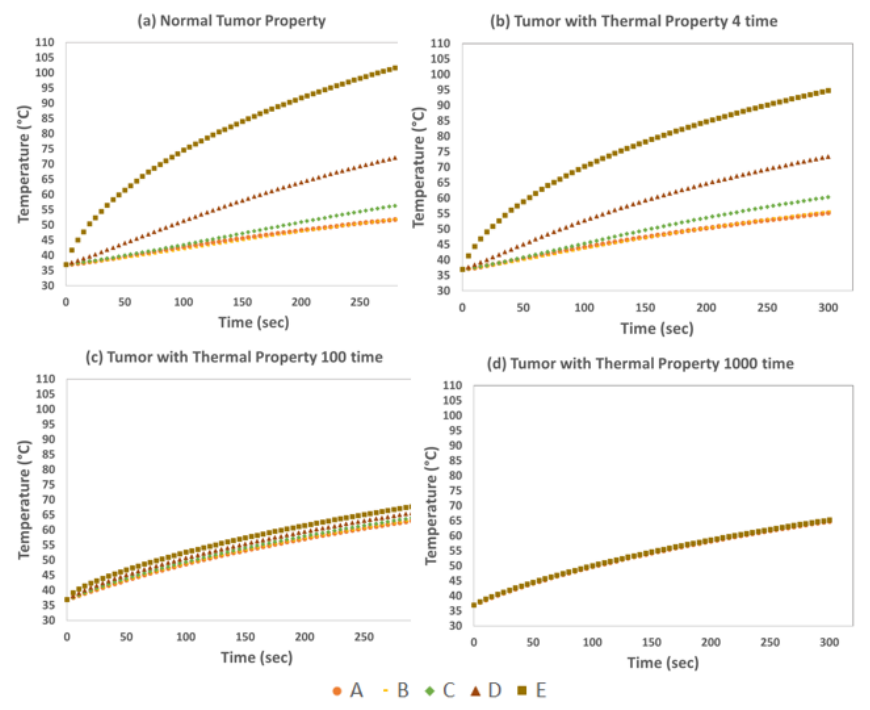

Figure 11. The temperature distribution along the arc section of tumor at various porous liver thermal conductivity properties: (a) Normal tumor thermal conductivity (b) Increase 4 time of normal tumor condition (c) Increase 100 time of normal tumor condition (d) Increase 1000 time of normal tumor condition

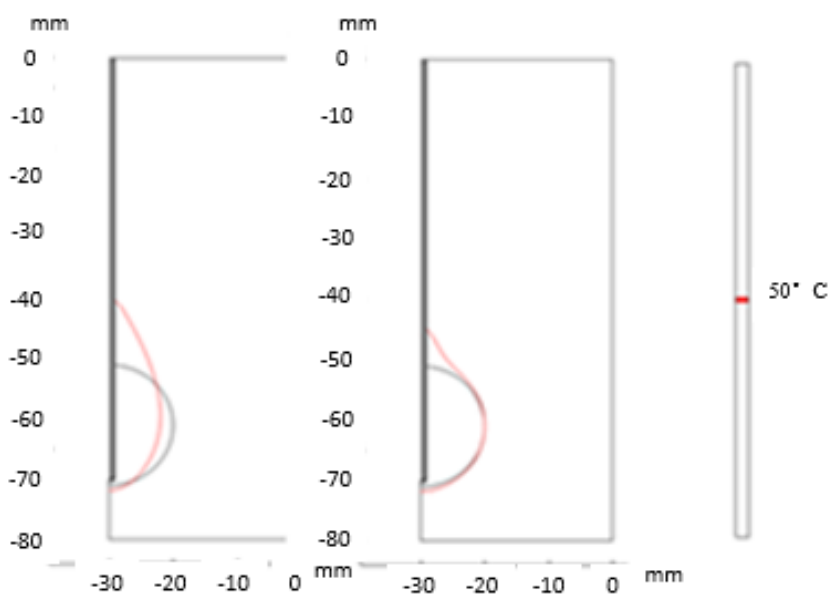

(a)

(b)

Figure 12. Temperature contour compare between (a) Normal tissue property and (b) increase 3 time for thermal and electrical conductivity

\section{CONCLUSION}

The Microwave ablation mathematical simulation model of heat transfer, as well as temperature profile within the porous liver, the coupled model of transport phenomenon of blood flow, heat transfer and electromagnetic wave propagation, has been developed. Specifically, study the influence of thermal and electrical properties on treatment outcome and efficacy. 
The model includes an accurately designed platform incorporates with blood flow. The mathematical model has been validated with the experimental data conducted by previous work [11]. It is found that the simulation result of the porous liver model has a better result than the conventional bioheat model when compared with previous experimental data [30].

Clinical treatment with MWA requires accurate control of various parameter due to the lesion creation need to create without effect on healthy tissue. To enhance the MWA process, the precious simulation model, porous liver model, has been proposed and two key properties, thermal and electrical conductivity, have been investigated. The key finding that emerged from this study include:

(1) The higher thermal conductivity is introduced to the targeted tumor tissue and found that the maximum temperature is reduced since the heat transfer and blood flow velocity in the proposed model phenomena. According to the result, the higher thermal conductivity effect to the maximum temperature and reduces the blood velocity. To promote heat transfer between MWA antenna and target tumor tissue, some particles having high thermal conductivity properties such as nanoparticle needed to introduce and investigate. To make an advantage point to absorb the maximum temperature and uniform lesion.

(2) The higher electrical conductivity is introduced to the targeted tumor tissue, the maximum temperature, and the heating rate are increased. The electrical conductivity enhances the performance of MWA in promoting the heat increasing rate and maximum temperature. This study results attributed to some particle having high electrical conductivity properties, for example, nanoparticle required to elevate magnitude of maximum temperature and heating rate between MWA and targeted tumor tissue.

(3) The higher thermal and electrical conductivity promotes the MWA to be more uniform temperature distribution in the tumor tissue. The higher thermal and electrical conductivity gives lower variation temperature in the targeted tumor. The backward heating effect can be decreased with this strategy as shown in Figure 12. This is very useful for elevate MWA efficiency and decreases the harmful during the MWA process.

This key investigation obtains the necessary aspects of a principle knowledge of heat transport within liver cancer and can be used as a guideline to study more for new hypothetical designs. Especially the properties of the selected nanoparticles assisted in the MWA process which can apply for further study.

\section{ACKNOWLEDGMENT}

The authors gratefully thank you for Thailand Science Research and Innovation and Thailand Government Budget Grant provided financial support for this work.

\section{REFERENCES}

[1] Simon, C.J., Duuy. D.E., Mayo-smith, W.W. (2005). Microwave ablation: Principles and application. Radiographics, 25: S69-S83. https://doi.org/10.1148/rg.25si055501

[2] McGahan, J.P., Brock, J.M., Tesluk, H., Gu, W.Z., Schneider, P., Browing, P.D. (1992). Hepatic ablation with use of radio-frequency electrocautery in the animal model. Journal of Vascular and Interventional Radiology, 3(2): 291-297.

[3] Goldberg, S.N., Gazelle, G.S., Mueller, P.R. (2000). Thermal ablation therapy for focal malignancy: A unified approach to underlying principles, techniques, and diagnostic imaging guidance. American Journal of Roentgenology, $\quad 174(2)$ : https://doi.org/10.1117/12.348726

[4] Kumar, D., Rai, K.N. (2016). A study on thermal damage during hyperthermia treatment based on DPL model for multilayer tissues using finite element Legendre wavelet Galerkin approach. Journal of Thermal Biology, 62: 170180. https://doi.org/10.1016/j.jtherbio.2016.06.020

[5] Lin, J.C., Bernardi, P., Pisa, S., Cavagnaro, M., Piuzzi, E. (2008). Antenna for Medical Theraphy and Diagnotics. Modern Antenna Handbook. C. Balanis, Ed., Newyork: Wiley. https://doi.org/10.1002/9780470294154.ch27

[6] Wonnel, T.L., Stauffer, P.R., Langberg, J.J. (1992). Evaluation of microwave and radio frequency catheter ablation in a myocardium-equivalent phantom model. IEEE Transactions on Biomedical Engineering, 39(10): 1086-1095. https://doi.org/10.1109/10.161341

[7] Lin, J.C., Wang, Y.L., Heriman, R.J. (1994). Comparison of power deposition pattern produced by microwave and radio frequency cardiac ablation catheters. Electronics Letters, 30(12): 922-923. https://doi.org/10.1049/el:19940682

[8] Deardorff, D.L., Diederich, C.J., Nau, W.H. (2001). Control of interstitial thermal coagulation: Comparative evaluation of microwave and ultrasound applicator. Medical Physics, 28(1): 104-117. https://doi.org/10.1118/1.1334606

[9] Attar, M.M., Haghpanahi, M., Amanpour, S., Mohaqeq, M. (2014). Analysis of bioheat equation for hyperthermia cancer treatment. Journal of Mechanical Science and Technology, 28(2): 763-771. https://doi.org/10.1007/s12206-013-1141-4

[10] Wright, A.S., Sampson, L.A., Warner, T.F., Mahvi, D.M. Lee, Jr. F.T. (2005). Radiofrequency versus microwave ablation in a hepatic porcine model. Radiology, 236: 132139. https://doi.org/10.1148/radiol.2361031249

[11] Keangin, P., Rattanadecho, P., Wessapan, T. (2011). An analysis of heat transfer in liver tissue during microwave ablation using single and double slot antenna. International Communications in Heat and Mass Transfer, 38(6): 757-766. https://doi.org/10.1016/j.icheatmasstransfer.2011.03.02 7

[12] Jiao, D., Qian, L., Zhang, Y., Zhang, F., Li, C., Huang, Z., Zhang, L., Zhang, W., Wu, P., Han, X., Duan, G., Han, J. (2010). Microwave ablation treatment of liver cancer with 2,450 MHz cooled-shaft antenna: an experimental and clinical study. Journal of Cancer Research and Clinical Oncology, 136(10): 1507-1516. https://doi.org/10.1007/s00432-010-0808-9

[13] Sun, Y., Cheng, Z., Dong, L., Zhang, G., Wang, Y., Liang, P. (2012). Comparison of temperature curve and ablation zone between 915 and $2450 \mathrm{MHz}$ cooled shaft microwave antenna: result in ex vivo porcine livers. European Journal of Radiology, 81(3): 553-557. https://doi.org/10.1016/j.ejrad.2011.02.013

[14] Brace, C.L., Van Der Weide, D.W., Lee Jr, F.T., Laeseke, P.F., Sampson, L. (2004). Analysis and experimental 
validation of a triaxial antenna for microwave tumor ablation. IEEE MTT-S International Microwave Symposium Digest, 3(6-11): 1437-1440. https://doi.org/10.1109/MWSYM.2004.1338842

[15] Brace, C.L., Laeseke, P.F., Sampson, L.A., Frey, T.M., Van Der Wiede, D.W., Lee Jr, F.T. (2007). Microwave ablation with multiple simultaneously powered small gauge triaxial antennas: result from an in vivo swine liver model. Radiology, 244(1): 151-156. https://doi.org/10.1148/radiol.2441052054

[16] Yang, D., Bertram, J.M., Converse, M.C., O’Rourke, A.P., Webster, J.G., Hagness, S.C., Will, J.A., Mahvi, D.M. (2006). A floating sleeve antenna yield localized hepatic microwave ablation. IEEE Transactions on Biomedical Engineering, 53(3): 533-537. https://doi.org/10.1109/TBME.2005.869794

[17] Prakash, P., Deng, G., Converse, M.C., Webster, J.G., Mahvi, D.M., Ferris, M.C. (2008). Design optimization of a robust sleeve antenna for hepatic microwave ablation. Physics in Medicine and Biology, 53(4): 1057-1069.

[18] Saito, K., Yoshimura, H., Ito, K., Aoyagi, Y., Horita, H. (2004). Clinical trials of interstitial microwave hyperthermia by use coaxial-slot antenna with two slots. IEEE Transactions on Microwave Theory and Techniques, $\quad 52(8)$ : https://doi.org/10.1109/TMTT.2004.832005

[19] Bertram, J.M., Yang, D., Converse, M.C., Webster, J.G., Mahvi, D.M. (2006). Antenna design for microwave hepatic ablation using an axisymmetric electromagnetic model. Biomedical Engineering Online, 5: 1-9. https://doi.org/10.1186/1475-925X-5-15

[20] Hadizafar, L., Azarmanesh, M.N., Ojaroudi, M. (2011). Enhance bandwidth double-fed microstrip slot antenna with a pair of L-shaped slots. Progress in Electromagnetics Research, 18: 47-57. https://doi.org/10.2528/PIERC10092812

[21] Bertram, J.M., Yang, D., Converse, M.C., Webster, J.G., Mahvi, D.M. (2006). A review of coaxial-based interstitial antennas for hepatic microwave ablation. Critical Reviews in Biomedical Engeering, 34(3): 187213.

https://doi.org/10.1615/CritRevBiomedEng.v34.i3.10

[22] Drewitz, M., Helbling, M., Fried, N., Bieri, M., Moritz, W., Lichtenberg, J., Kelm, J.M. (2011). Towards automated production and drug sensitivity testing using scaffold-free spherical tumor microtissues. Biotecnology Journal Special Issue: Scaffold-Free Cell-Based Systems, $6(12)$ : https://doi.org/10.1002/biot.201100290

$1488-1496$

[23] Clark, P.E., Wooddruff, R.D., Zagoria, R.J., Hall, M.C. (2007). Microwave ablation of renal parenchymal tumors before nephrectomy: phase I study. American Journal of Roentgenoiogy, 188(5):

1212-1214. https://doi.org/10.2214/AJR.05.2190

[24] Phasukkit, P., Tungjitkusolmun, S., Sangworasil, M. (2009). Finite-element analysis and in vitro experiments of placement configurations using triple antennas in microwave hepatic ablation. IEEE Transactions on Biomedical Engineering, 56(11): 2564-2572. https://doi.org/10.1109/TBME.2009.2027128

[25] Li, M., Yu, X.L., Liang, P., Liu, F., Dong, B., Zhou, P. (2012). Percutaneous microwave ablation for liver cancer adjacent to the diaphragm. International Journal

of Hyperthermia, 28(3): 218-226. https://doi.org/10.3109/02656736.2012.665565

[26] Kaled, A.R.A., Vafai, K. (2003). Review: The role of porous media in modeling flow and heat transfer in biological tissues. International Journal of Heat and Mass transfer, 46: 4989-5003. https://doi.org/10.1016/S00179310(03)00301-6

[27] Mahajoob, S., Vafai, K. (2009). Analytical characterization of heat transport through biological media incorporating hyperthermia treatment. International Journal of Heat and Mass Transfer, 52(5-6): $1608-1618$

https://doi.org/10.1016/j.ijheatmasstransfer.2008.07.038

[28] Stauffer, P.R., Rossetto, F., Prakash, M., Neuman, D.G., Lee, T. (2003). Phantom and animal tissue for modeling the electrical properties of human liver. International Journal of Hyperthermia, 19(1): 89-101. https://doi.org/10.1080/0265673021000017064

[29] Wessapan, T., Srisawatdhisukul, S., Rattanadecho, P. (2011). The effects of dielectric shield on specific absorption rate and heat transfer in the human body exposed to leakage microwave energy. International Communications in Heat and Mass Transfer, 38(2): 255262.

https://doi.org/10.1016/j.icheatmasstransfer.2010.12.00 4

[30] Yang, D., Converse, M., Mahvi, D.M., Webster, J.G. (2007). Expanding the bioheat equation to include tissue internal water evaporation during heating. IEEE Transactions on Biomedical Engineering, 54(8): 13821388. https://doi.org/10.1109/TBME.2007.890740

[31] Rattanadecho, P., Keangin, P. (2013). Numerical study of heat transfer and blood flow in two-layered porous liver tissue during microwave ablation process using single and double slot antenna. International Journal of heat and mass Transfer, 58(1-2): 457-470. https://doi.org/10.1016/j.ijheatmasstransfer.2012.10.043

[32] Brinkman, H.C. (1949). On the permeability of media consisting of closely packed porous particles. Flow, Turbulence and Combustion, 1: 81-86. https://doi.org/10.1007/BF02120318

\section{NOMENCLATURE}

Z

$k$

$C$

$\frac{R}{H}$

$H$

P,

$d_{p}$

$C_{p}$

$\vec{E}$

$g$

K

$P$

$Q$

t wave impedance in the dielectric of the coaxial cable $(\Omega)$ propagation constant $\left(\mathrm{m}^{-1}\right)$ speed of light $(\mathrm{m} / \mathrm{s})$ dielectric radius $(\mathrm{m})$ Magnetic field (A/m) velocity component $(\mathrm{m} / \mathrm{s})$

pressure $(\mathrm{Pa})$ diameter of cell tissue $(\mathrm{m})$ specific heat capacity $\left(\mathrm{J} / \mathrm{kg}{ }^{\circ} \mathrm{C}\right)$

Electric field $(\mathrm{V} / \mathrm{m})$ gravitation constant $\left(\mathrm{m}^{2} / \mathrm{s}\right)$ thermal conductivity $\left(\mathrm{W} /\left(\mathrm{m}^{\circ} \mathrm{C}\right)\right.$ input microwave power $(\mathrm{W})$ heat source $\left(\mathrm{W} / \mathrm{m}^{3}\right)$ time (s) temperature $\left({ }^{\circ} \mathrm{C}\right)$ 


\section{Greek symbols}

$\omega \quad$ angular frequency ( $\mathrm{rad} / \mathrm{s})$

$\rho \quad$ density of liver tissue $\left(\mathrm{kg} / \mathrm{m}^{3}\right)$

$\varepsilon_{0} \quad$ permittivity of free space $(\mathrm{F} / \mathrm{m})$

$\varepsilon_{r} \quad$ relative permittivity (-)

$\mu \quad$ permeability $(\mathrm{H} / \mathrm{m})$

$\mu_{r} \quad$ relative permeability

$v \quad$ kinematics viscosity $\left(\mathrm{m}^{2} / \mathrm{s}\right)$

$\phi \quad$ tissue porosity

$\kappa \quad$ permeability $\left(\mathrm{m}^{2}\right)$

$\beta \quad$ coefficient of thermal expansion $\left(\mathrm{K}^{-1}\right)$ electric conductivity $(\mathrm{S} / \mathrm{m})$

\section{Subscripts}

$\begin{array}{ll}b & \text { blood/fluid phase } \\ t & \text { tissue/solid phase } \\ \text { eff } & \text { effective value } \\ \text { ext } & \text { external } \\ \text { inner } & \text { inner } \\ \text { liver } & \text { liver } \\ \text { met } & \text { metabolism } \\ \text { outer } & \text { outer } \\ r, z, \varphi & \text { component of cylindrical coordinates }\end{array}$

